\title{
REFLEXOS DO CURRÍCULO OCULTO NA CONSTRUÇÃO DA IDENTIDADE E SUBJETIVIDADE DO SER
}

\author{
REFLECTIONS OF THE HIDDEN CURRICULUM IN THE CONSTRUCTION OF THE \\ IDENTITY AND SUBJECTIVITY OF THE BEING
}

\author{
Marcos Toledo \\ Universidade de Uberaba, Uberaba, MG, Brasil. E-mail: toledomarcos@outlook.com.br
}

\section{François Ramos}

Faculdade Presidente Antônio Carlos, Uberaba, MG, Brasil. E-mail: francois.ramos@hotmail.com

DOI: https://doi.org/10.46550/amormundi.v2i2.58

Recebido em: 17.01.2021

Aceito em: 19.02.2021

\begin{abstract}
Resumo: Trazendo uma análise sobre o currículo por meio da abordagem de sua conceitualizaçáo como bem dos seus tipos previstos por leis que regem o tema - sendo eles o currículo real, formal e oculto -, o presente artigo tem por objetivo principal as abordagens do currículo oculto e das consequências que este pode causar na formação do ser diante da identidade e da subjetividade do mesmo. A abordagem em questão contará com exemplificaçôes de casos reais e comumente presenciados dentro das instituiçóes escolares e de tratativas de modelos pedagógicos que geralmente são instituídos. Destarte, serão expressos e fundamentadas questôes pertinentes responsabilidade do docente no exercício da profissão e a imprescindibilidade de se pautar nas diretrizes instituição através de leis. Para idealização do presente trabalho foram realizadas diversas pesquisas bibliográficas e hipertextuais, além de pesquisas documentais de materiais que versavam sobre o currículo. Logo, à conclusão tomada em relação ao fato é de que o professor detém de responsabilidade na construção da identidade de seus alunos por meio da subjetividade em que o mesmo realiza suas atividades profissionais.
\end{abstract}

Palavras-chave: Currículo; Currículo oculto; Identidade; Subjetividade.

Abstract: Bringing an analysis of the curriculum through the approach of its conceptualization as well as of its types foreseen by laws that govern the theme - being the real, formal and hidden curriculum -, this article has as main objective the approaches of the hidden curriculum and of the consequences that this can cause in the formation of the being in the face of its identity and subjectivity. The approach in question will feature examples of real cases and commonly seen within school institutions and dealings with pedagogical models that are usually instituted. In this way, pertinent issues regarding the teacher's responsibility in the exercise of the profession and the need to be guided by the institution guidelines through laws will be expressed and substantiated. For the idealization of the present work, several bibliographic and hypertext searches were carried out, in addition to documentary searches of materials that dealt with the curriculum. Therefore, the conclusion taken in relation to the fact is that the teacher has responsibility for building the identity of his students through the subjectivity in which he performs his professional activities.

Keywords: Curriculum; Hidden curriculum; Identity; Subjectivity. 


\section{Notas introdutórias}

presente trabalho expôe uma breve análise sobre o currículo, explanando de forma sintetizada o seu conceito e abordando diretamente a caracterização como também as distinçôes entre cada um dos seus tipos, que são: currículo real, currículo formal e currículo oculto. Diante das abordagens, o trabalho possui por foco principal as abordagens do currículo oculto, sendo as tratativas de tal o objetivo principal e, diante dessa abordagem, será explanado sobre os reflexos que este vem a causar na construção da identidade e da subjetividade dos educandos a quem deste currículo estão submissos.

Para o desenvolvimento deste, serão utilizadas exemplificaçóes de atos imperceptíveis que são vivenciados diariamente diante do contexto educacional, sendo selecionados e expressados referenciando sua inserção nos modelos pedagógicos já instituídos e nas formas de ensino que são atualmente desenvolvidas, não necessitando de um contexto específico, estando presente diante de todas as instituições escolares, não havendo barreiras culturais, regionais, financeiras, entre outras possibilidades.

Inserido neste mesmo contexto será explanado sobre a responsabilidade que detém o docente no exercício da sua profissão, como os reflexos que podem causar as açôes desenvolvidas por ele diante da formaçáo dos educandos à quem leciona, destacando a imprescindibilidade de se basear nas diretrizes instituídas por lei para a elaboração dos planos de aula.

Como metodologia do trabalho em questão foram realizadas pesquisas bibliográficas e hipertextuais, utilizando de obras que versam a temática "Currículo" e de sites como SciELO e Google Acadêmico para a busca de trabalhos que abordam temáticas similares e que relatam aspectos do currículo (principalmente oculto) diante do contexto educacional. Foram utilizados os descritores 'subjetividade', 'currículo' e 'currículo oculto' para efetivação da pesquisa.

Através do procedimento metodólogo foi permitido a junção de materiais que embasaram todo o trabalho como também foi permitido a idealização de ideias que leva a compreensão de que a identidade e a subjetividade dos educandos são formadas através dos ensinamentos dirigidos pelo docente, sendo de forma escrita ou oral, ou seja, o aprendizado do discente está além dos ensinamentos expressos pelo currículo real e pelo currículo formal, mas sua construção se encontra intrínseco as atitudes que o docente possui, os pensamentos que detém e a forma com que esse se porta diante das situações diárias.

\section{Currículo: conceitualizaçáo e aspectos}

Conforme Pacheco (2007, p. 48), o termo currículo vem do latim curriculum que significa lugar onde se corre ou corrida, derivado do verbo currere que quer dizer percurso a ser seguido ou carreira. O presente sentido leva a compreensão de que o currículo é o conteúdo a ser estudado ou mesmo um curso a ser seguido almejando processos definidos de ensino-aprendizagem.

O estudo do termo currículo pode causar distintas interpretaçóes, o que ocorre diante de sua conceitualização polissêmica, variando do contexto em que está inserido como também da maneira que o termo vem a ser empregado. Neste sentido é que Gimeno Sacristán (2013, p. 9-10) reconhece que "essas peculiaridades - entre outras - fazem o conceito do currículo se referir a uma realidade difícil de explicar por meio de uma definição simples, esquemática e 
esclarecedora, devido à própria complexidade do conceito”.

No contexto exposto, para Sacristán (1995), currículo seria “a cultura que se origina de vários processos, não se restringindo a um objeto estático e delimitado, que se planeja e se implanta posteriormente”. Porém, para Galeão (2005), “o currículo consiste num conjunto organizado de disciplinas distribuídas de forma variada ao longo do processo de escolarização", já para Silva (2003) "o currículo é texto, discurso, documento. O currículo é documento de identidade".

Portanto, mesmo diante da complexidade de sua conceitualização, fruto de inúmeras tratativas e possibilidades, no fundo das teorias do currículo está, pois, uma questão de "identidade" ou de "subjetividade", fato este que objetiva a relevância do currículo diante da construção da identidade de educandos, estando intrínseco à forma de ver, interpretar e analisar o mundo que o rodeia (SILVA, 2003, p. 15).

Sua relevância se justifica na exigência da evidenciação dos currículos em documentos oficiais, seja em nível nacional (nos documentos oficiais como leis, normas e diretrizes nacionais, livros didáticos, propostas curriculares) ou nível local, como os planos de ensino e planos de aula que são elaborados pelos professores (ARAUJO, 2018, p. 30). Diante deste contexto é imprescindível ressaltar que, ainda que seja de correspondência local, a elaboração dos planos de aula devem se submeter às leis instituídas em cunho nacional.

Ainda que expresso a conceituação de currículo e suas caracterizaçóes como formal, real e oculto, o presente trabalho se objetiva estritamente num aspecto: no contexto escolar, o que se tem aprendido - por parte dos educandos - está além do que o currículo prescrito expóe, indicando à concepção de um currículo oculto, caracterizado por Silva (2003, p. 78) como sendo "constituído por todos aqueles aspectos do ambiente escolar que, sem fazer parte do currículo oficial, explícito, contribuem, de forma implícita, para aprendizagens sociais relevantes”. Destarte, compreende-se que através deste aprende valores e orientações da sociedade que versam sobre seu funcionamento e sua estruturação, por meio do docente.

Para fundamentar o posicionamento, o presente artigo se baseia nas consideraçôes de Veiga (2000, p. 107) na afirmação de que

Por exigir uma interação entre professores ealunos a dinâmica ensino-aprendizagem escolar envolve fatores afetivos e sociais. Essa relação implica um vínculo direto com o meio social que inclui as condiçóes de vida do educando, a sua relação com a escola, sua percepção e compreensão do conhecimento sistematizado a ser estudado. $\mathrm{O}$ trabalho docente é a atividade que dá unidade à dinâmica ensinoaprendizagem pelo processo de mediaçáo entre conhecimento a ser aprendido e a ação de apropriação desse conhecimento.

As consideraçôes demonstram a imprescindibilidade da análise e estudo do currículo na tratativa do ser que está sendo formado, da finalidade do conhecimento que está sendo transmitido e o que está, realmente, sendo ensinado - pelos educadores - nas instituiçóes escolares.

\section{Os tipos de currículo e seus reflexos}

Anterior às tratativas de currículo oculto é necessário a exposição da conceituação de currículo, bem como a explanaçáo de seus tipos. Para Sacristán (1998, p. 46), o currículo aparece como "conjunto de objetivos de aprendizagem selecionados que devem dar lugar à criação de 
experiências apropriadas que tenham efeitos cumulativos avaliáveis".

Moreira (2000, p. 11), no mesmo contexto sobre o conceito de currículo, cita que este

Constitui significativo instrumento utilizado por diferentes sociedades tanto para desenvolver os processos de conservação, transformação e renovação dos conhecimentos historicamente acumulados como para socializar crianças e jovens segundo valores tido como desejáveis.

Indo além da simples conceituação e referenciando as tratativas de seu tipo, segundo Silva (2003), no currículo há a categorização de três níveis, que os classificam como podendo ser formal, real e/ou oculto.

$\mathrm{Na}$ caracterização do currículo formal, temos aquele que é estabelecido por diretrizes governamentais e estruturado por normativas prescritas, que almeja oferecer uma base comum a educação em nível nacional. Está assegurado pela lei 9.394 de 1996. Apresenta também uma outra base obrigatória que está pautada na formação de conteúdos complementares seguindo o contexto local e regional de cada instituição escolar.

Sobre este tipo de currículo, Libâneo (2001, p. 99) cita:

Refere-se ao currículo estabelecido pelos sistemas de ensino ou instituição educacional. É o currículo legal expresso em diretrizes curriculares, objetivos e conteúdos das áreas ou disciplinas de estudo. O currículo formal ou oficial é aquele conjunto de diretrizes normativas prescritas institucionalmente, como, por exemplo, os Parâmetros Curriculares Nacionais divulgados pelo Ministério da Educação, as propostas curriculares dos Estados e Municípios.

Já o currículo real é a tratativa do que está, efetivamente, sendo ensinado aos alunos pelo professor, ou seja, a parte prática do currículo formal. Sobre este, Libâneo (2001, p. 99) explicita que

É a execução de um plano, é a efetivação do que foi planejado, mesmo que nesse caminho do planejar e do executar aconteçam mudanças, intervenção da própria experiência dos professores, decorrentes de seus valores, crenças, significados. É o currículo que sai da pratica dos professores, da percepção e do uso que os professores fazem do currículo formal assim como o que fica na percepção dos alunos.

$\mathrm{Na}$ evidência do currículo oculto, tem-se a caracterização de que este é formado a partir de aspectos do ambiente escolar que náo estáo explicitados no currículo formal, contribuindo para aprendizagens. O currículo oculto representa tudo o que os alunos aprendem pela convivência espontânea em meio as várias práticas, atitudes, comportamentos, gestos, percepçóes, que vigoram no meio social e escolar (LIBÂNEO, 2001, p. 100).

Diante do contexto, é notável a caracterização (como decorrente de um currículo oculto) o aprendizado de valores e comportamentos, que embasarão as atitudes do educando diante da sociedade em que este está inserido, por meio da estruturação de seu aprendizado subjetivo.

Nas palavras de Silva (2003),

No fundo das teorias do currículo está, pois, uma questão de "identidade" ou de "subjetividade". Se quisermos recorrer à etimologia da palavra "currículo", que vem do latim curriculum, "pista de corrida", podemos dizer que no curso dessa "corrida" que é o currículo acabamos por nos tornar o que somos. Nas discussóes cotidianas, quando pensamos em currículo pensamos apenas em conhecimento, esquecendo-nos de que o conhecimento que constitui o currículo 
está inextricavelmente, centralmente, vitalmente, envolvido naquilo que somos, naquilo que nos tornamos: na nossa identidade, na nossa subjetividade.

Ao expressar a relação de currículo como questão de identidade ou de subjetividade, Silva (2003, p. 15-16) fundamenta seu posicionamento expressando que,

Nas discussões cotidianas, quando pensamos em currículo pensamos apenas em conhecimento, esquecendo-nos de que o conhecimento que constitui o currículo está inextricavelmente, centralmente, vitalmente, envolvido naquilo que somos, naquilo que nos tornamos: na nossa identidade, na nossa subjetividade. Talvez possamos dizer que, além de uma questão de conhecimento, o currículo é também uma questáo de identidade.

Analisando a teoria de enfoque, remete-se ao processo de dominação que permeia a sociedade em vários de seus seguimentos (como de classes sociais, raça, gênero e etnia), que está instituído em forma do que é comum, adentrando nas sociedades de forma subjetiva, levando à compreensão própria do ser como produto social que está completamente inserida na educaçáo. Os docentes, em suas rotulaçôes de educandos, é um exemplo crítico prático da normalização do processo de dominação que referencia o currículo oculto.

A representação dos educandos - por parte dos educadores -, que acarretará - de forma benéfica ou maléfica - o desenvolvimento escolar do educando, se dá em duas maneiras distintas, sendo elas a objetiva e a subjetiva. Araújo (2018, p. 35) as exemplificam na prática do seguinte modo

Objetivamente isso é observado por meio da avaliação, das notas, conceitos e classificaçóes dos alunos, instrumentos objetivos que fazem parte da estrutura organizacional da escola. Subjetivamente esses juízos estão presentes nos comentários, mímicas de desagrado, irritação, intolerância, desprezo, etc.

Esta rotulação transmite aos educandos - de modo subjetivo -, formas de comportamento que levarão à compreensão de que uns sobressaem aos outros, uns possuem inteligência enquanto outros são desprovidos desta, além da interpretação de que alguns educandos não deveriam sequer estar dentro de uma instituição escolar, participando de sua comunidade. Essa aprendizagem é uma tratativa do currículo oculto.

Silva (1996, p. 3), referenciando as consequências do currículo oculto, se posiciona ao dizer que "o currículo oculto tem como função ideológica, através do critério do "esforço pessoal", preparar os alunos ou para serem dominados ou para serem dominantes neste tipo de sociedade em que vivemos".

Fundamenta, simultaneamente, que os valores existentes em um currículo oculto têm ligação com a sociedade cujo está inserido. Destarte, discorre ainda que

Numa sociedade competitiva como a nossa, a escola também é competitiva, porque nela só se dão bem os "melhores", e é neste tipo de escola que os filhos da classe privilegiada descobrem, muito cedo, a sua "superioridade" e os demais, a sua "inferioridade" (SILVA, 1996, p. 3).

Nisto está a imprescindibilidade da atenção dos docentes diante do contexto de aprendizagem, onde por sua vez, empregam ideologias ao incorporar estratégias e métodos diante do ensino, como também a seleção de conteúdos e suas avaliações. Na ausência deste olhar malicioso, as instituiçôes escolares tem omitido sua responsabilidade na função social na transmissão de habilidades e valores como a honestidade, o orgulho da herança racial e da 
abertura para o ser intelectual (ARAÚJO, 2018, p. 37).

\section{Aspectos metodológicos}

A presente pesquisa está referenciada em abordagens qualitativas e descritivas. Nas palavras de Minayo (2009), "a pesquisa qualitativa se ocupa, nas Ciências Sociais, com um nível de realidade que não pode ou não deveria ser quantificado”. No sentido, Gil (1999) colabora em seus dizeres de que métodos de pesquisas qualitativas estão voltados para auxiliar os pesquisadores a compreenderem pessoas e seus contextos sociais, culturais e institucionais.

Nas tratativas do desenvolvimento da pesquisa descritiva, a fundamentação se baseia na expressão de Gil (1999) de que esta possui por objetivo primordial "a descrição das características de determinada população, fenômeno ou, então, o estabelecimento de relaçôes entre as variáveis”.

O referencial teórico e metodológico abordados neste trabalho foram fundamentados grandes autores que desenvolvem trabalhos relevantes sobre a temática proposta.

\section{Consideraçóes finais}

O currículo escolar é formado por todas as aprendizagens que são realizadas dentro do ambiente escolar, portanto, não é possível categorizá-lo como sendo neutro, devendo o mesmo ser caracterizado como ideológico por estar carregado de interesses políticos, econômicos e culturais (ARAÚJO, 2018, p.38).

Portanto, cabe ao docente a incumbência do ensino daquilo que está ou não no currículo prescrito por meio do desenvolvimento de suas atividades como educador, pois estas refletirão diretamente na formação do educando a quem está lecionando diariamente por meio das formas como se porta diante das situaçôes bem como das perspectivas de visão que possui em relação aos fatos de uma sociedade.

Na mesma linha de raciocínio e seguindo algumas teorias pós-críticas, tem-se a indicação de que o currículo oculto é uma construção cultural, pois este sinaliza ideologias e as impóe sobre determinados grupos. Consequente, sua discussão é necessária por estar presente em todas as instituiçôes escolares, independente da cultura que esta exerça e do contexto de sua inserção.

Destarte, subentende-se que formação dos educandos são, em grande parte, decorrentes do currículo oculto, ou seja, tudo que lhes são ensinados de maneira implícita contribui para a formação de sua identidade e de sua subjetividade, por meio da criação de suas representações de valores e pensamentos.

Sendo os valores, habilidades, orientaçóes e atitudes, pertencentes ao currículo - prescrito ou oculto - transmitidos pelo docente, a responsabilidade pela formação da identidade e subjetividade do educando está nas mãos do próprio educador, devendo este compreender a sua responsabilidade e a desenvolver suas atividades de forma consciente, almejando êxito na sua primordial atividade que é educar. 


\section{Referências}

ARAUJO, V. P. C. O conceito de currículo oculto e a formaçáo docente. REAe - Revista de Estudos Aplicados em Educação, v. 3, n. 6, jul./dez. 2018. Disponível em: <https://seer.uscs. edu.br/index.php/revista_estudos_aplicados/article/view/5341>.

CASTRO, Mariângela Machado. $\mathbf{O}$ conceito de currículo oculto em artigos publicados na biblioteca eletrônica SciELO (2001 - 2015). Dissertação de Mestrado. São Carlos/SP: PPGE/UFSCar, 2017.

GALEÃO, R. F. B. C. Desenvolvimento curricular: análise de projectos curriculares. Monografia. 6-76, 2005.

GIL, A. C. Métodos e técnicas de pesquisa social. 5. ed. São Paulo: Atlas, 1999.

GIMENO SACRISTÁN, J. (Org.). Saberes e incertezas sobre o currículo. Porto Alegre: Penso, 2013.

LIBÂNEO, Antônio Carlos, Organização e gestáo da escola: teoria e pratica - Goiania: ed. Alternativa, 2001.

MINAYO, M. C.S. O desafio do conhecimento. Pesquisa qualitativa em saúde. 2.ed. São Paulo: HUCITEC/ Rio de Janeiro: ABRASCO, 2009.

MOREIRA, A. F. e SILVA, T. T. (org.) Currículo, cultura e sociedade. 4. ed. São Paulo: Cortez, 2000.

PACHECO, M. M. D. R. Currículo, interdisciplinaridade e organizaçáo dos processos de ensino. Fundação Hermínio Ometto / Uniararas, 2007.

SACRISTÁN, José Gimeno. O currículo: uma reflexáo sob a prática. 3. ed. Porto Alegre: Artes Médicas, 1998.

SACRISTÀN, José Gimeno. O que significa o currículo? In: Saberes e incertezas sobre o currículo. Porto Alegre: Penso, 2013.

SILVA, Maria José Lopes. Um aspecto da função ideológica da escola: o currículo oculto. Boletim Técnico do SENAC. v. 22, n.2, maio/agosto 1996. Disponível em: <https://www.oei. es/historico/na2003.htm>.

SILVA, Tomaz Tadeu da. Documentos de identidade: uma introdução às teorias do currículo. 2. ed. Belo Horizonte: Autêntica, 2003.

VEIGA, I. P. A. Didática: o ensino e suas relaçôes. São Paulo: Papirus, 2000. 